\title{
(2) OPEN ACCESS \\ Differences in flavourant levels and synthetic coolant use between USA, EU and Canadian Juul products
}

\author{
Hanno C Erythropel (0) 1,2 Paul T Anastas, ${ }^{3}$ Suchitra Krishnan-Sarin, ${ }^{2}$ \\ Stephanie S O'Malley, ${ }^{2}$ Sven Eric Jordt, ${ }^{2,4}$ Julie B Zimmerman ${ }^{1,2}$
}

${ }^{1}$ Department of Chemical and Environmental Engineering, Yale University, New Haven, Connecticut, USA

${ }^{2}$ Center for the Study of Tobacco Products Use and Addiction: Flavors, Nicotine, and Other Constituents, Department of Psychiatry, Yale University School of Medicine, New Haven, Connecticut, USA

${ }^{3}$ School of Public Health, Yale School of Medicine, New Haven, Connecticut, USA

${ }^{4}$ Department of Anesthesiology, Duke University School of Medicine, Durham, North Carolina, USA

Correspondence to

Professor Julie B Zimmerman, Dept. of Chemical \&

Environmental Engineering, Yale University, New Haven, Connecticut, USA julie.zimmerman@yale.edu

Received 7 November 2019 Revised 27 February 2020 Accepted 10 March 2020 Published Online First 27 April 2020

\section{ABSTRACT}

Background 'Juul' is the dominant US e-cigarette brand and was recently introduced to Canada, UK, France, Germany and Italy, with several flavours available across countries. US/ Canadian products are sold with 5\%, 3\% and 1.5\% (Canada only) nicotine content, whereas European Union (EU) regulation limits nicotine content to $1.7 \%$. The differential nicotine content raises the question if flavour profiles and Juul device power output differ between countries.

Methods 'Mint', 'Vanilla' and 'Mango' e-liquids from all six countries were purchased in 2019 and analysed by GC/MS for their principal flavourant and nicotine content. In addition, device power specifications were compared for devices purchased from the respective countries.

Results Compositions of Juul e-liquids from the USA and Canada were identical and differed from the EU-marketed liquids, in which principal flavourant concentrations were significantly lower. EU Juul 'Mint' e-liquids contained a synthetic coolant, N-ethyl-p-menthane-3-carboxamide (WS3), absent in US/Canadian products. US/Canadian 'Mango' e-liquid contained triethyl-citrate, an emulsifier. Nicotine contents matched label information, and devices had identical power specifications.

Conclusions Tested US/Canadian Juul e-liquids contained higher flavour concentrations than EU products, likely reflecting adaptation to user preferences. In EU, 'Mint' e-liquid, menthol is partially substituted with the synthetic coolant WS-3 that elicits a cooling effect like menthol but lacks its distinct 'minty' odour. The inhalational safety of WS-3 is unknown. The use of an emulsifier in US/Canadian 'Mango' Juul e-liquid may be necessary to keep the product homogeneous. Similar power specifications of devices between countries suggest that nicotine aerosol delivery is likely proportional to the e-liquid nicotine content.

\section{INTRODUCTION}

Since 2017, Juul electronic cigarettes have dominated the US market ${ }^{1}$ with sales expanding to the UK (July 2018), Canada (September 2018), France, Germany (both December 2018), and Italy (January 2019). While US and Canada-marketed Juul e-liquid 'pods' are sold with nicotine concentrations of $59 \mathrm{mg} / \mathrm{mL}$ $(5 \%), 35 \mathrm{mg} / \mathrm{mL}(3 \%)$ and $18 \mathrm{mg} / \mathrm{mL}(1.5 \%$, only Canada), European Union (EU) regulations limit nicotine content to $20 \mathrm{mg} / \mathrm{mL}(1.7 \%)$ in e-liquids. ${ }^{2}$ The reduced nicotine concentration likely alters the user experience, raising the question if other characteristics differ, such as flavour profiles that counter nicotine's bitter taste, or the device power output which influences nicotine delivery per puff. Therefore, this study aimed to elucidate differences in flavourant concentrations and power specifications between US, Canadian and EU-marketed Juul products to inform e-cigarette regulations.

\section{METHODS}

Juul 'pods' of all available flavours per country and devices were purchased online (USA) or in stores (Canada, UK, Italy, France, Germany) during May to June 2019. Flavour availability differed by country, but 'Mint', 'Vanilla' (also sold as 'Crème Brulée' and 'Royal Cream'), 'Mango' and one 'Tobacco' flavour were available in every country (table 1). Samples from three pods of 'Mint', 'Vanilla' and 'Mango' flavours from each country were analysed for principal flavourant content and nicotine was quantified in all flavours from all countries in triplicate $(n=153)$ using established GC/MS protocols. ${ }^{3}$ Commercially available standards were used for quantification. To compare Juul device specifications between the six countries, devices were opened, printed battery specs were compared and voltage output verified using a digital multimeter. In addition, the coil resistance was measured for at least three differently flavoured pods per country, as the device power output ( $\mathrm{P}$ in watt) is a function of battery voltage ( $V$ in volt) and coil resistance ( $R$ in ohm), calculated according to equation 1 .

$$
\left.P=\frac{V^{2}}{R} \text { (equation } 1\right)
$$

\section{RESULTS}

The compositions of the European (UK/Italian/French/ German) Juul e-liquids were nearly identical and differed from USA and Canadian liquids. Flavourant concentrations in US/Canadian e-liquids were identical and did not vary with nicotine concentrations. The concentrations of the principal flavourants of 'Mint' (menthol), 'Vanilla' (vanillin) and 'Mango' flavours ( $\delta$-undecalactone, ethyl-butyrate) were comparable in the US and Canadian products, yet significantly lower in European products (figure 1). The synthetic coolant WS-3 (N-ethyl-p-menthane-3-carboxamide, CAS\#39711-79-0) was found only in EU 'Mint' flavour. Mango flavour contained compounds exclusive to US/Canadian e-liquids (emulsifier triethyl citrate, $0.45 \mathrm{mg} / \mathrm{g}(0.03)$; ethyl maltol, $1.68 \mathrm{mg} / \mathrm{g}(0.06))$ and to EU e-liquid (benzyl alcohol, $1.39 \mathrm{mg} / \mathrm{g}(0.05))$. 'Vanilla' e-liquids from every country contained acetals, the previously reported reaction products of vanillin with propylene glycol/glycerol. ${ }^{1}{ }^{3}$ Measured nicotine concentrations agreed with labels (table 1) and equimolar amounts of benzoic acid were detected in all sampled products, suggesting that nicotine was in salt form. Batteries and coil resistance were identical for devices from all countries: $3.7 \mathrm{~V}$ (battery output), 
Table 1 Juul flavour availability and name per country, underlaid with characteristic colour of the respective flavour pod

\begin{tabular}{|c|c|c|c|c|c|c|c|c|c|}
\hline \multirow[b]{2}{*}{ Flavour } & \multicolumn{9}{|c|}{ Name by country } \\
\hline & \multicolumn{2}{|l|}{ USA } & \multicolumn{3}{|l|}{ Canada } & UK & Italy & France & Germany \\
\hline Mint & \multicolumn{2}{|l|}{ Mint } & \multicolumn{3}{|l|}{ Mint } & Glacial Mint & Mint & Mint & Mint \\
\hline Vanilla & \multicolumn{2}{|c|}{ Crème Brulee } & \multicolumn{3}{|l|}{ Vanilla } & Royal Crème & Vanille & Royal Crème & Royal Crème \\
\hline Mango & \multicolumn{2}{|l|}{ Mango } & \multicolumn{3}{|l|}{ Mango } & Mango Nectar & Mango & Mango & Mango \\
\hline Tobacco I & \multicolumn{2}{|c|}{ Virginia Tobacco } & \multicolumn{3}{|c|}{ Virginia Tobacco } & - & - & - & Rich Tobacco \\
\hline Tobacco II & \multicolumn{2}{|c|}{ Classic Tobacco* } & \multicolumn{3}{|c|}{-} & Golden Tobacco & Golden Tobacco & Blond Royal & - \\
\hline Fruit & \multicolumn{2}{|c|}{ Fruit } & \multicolumn{3}{|l|}{ Fruitt } & - & - & - & - \\
\hline Cucumber & \multicolumn{2}{|c|}{ Cool Cucumber } & \multicolumn{3}{|c|}{ Cool Cucumber } & - & - & - & - \\
\hline Menthol & \multicolumn{2}{|c|}{ Menthol* } & \multicolumn{3}{|c|}{-} & - & - & - & - \\
\hline Berry & \multicolumn{2}{|l|}{-} & \multicolumn{3}{|l|}{-} & Alpine Berry & - & - & - \\
\hline Apple & \multicolumn{2}{|l|}{-} & \multicolumn{3}{|l|}{-} & Apple Orchard & - & Pomme & Apple \\
\hline \multicolumn{10}{|c|}{ Nicotine concentrations in weight- $\%$} \\
\hline Flavour & \multicolumn{2}{|l|}{ USA } & \multicolumn{3}{|l|}{ Canada } & \multicolumn{4}{|c|}{ EU (UK, Italy, France, Germany) } \\
\hline Labelled & 5 & 3 & 5 & 3 & 1.5 & \multicolumn{4}{|c|}{$1.7 \%$} \\
\hline $\begin{array}{l}\text { Measured } \\
\text { Mean }(95 \% \mathrm{Cl})\end{array}$ & $5.3(0.1)$ & $3.1(0.1)$ & $4.9(0.4)$ & $2.9(0.3)$ & $1.5(0.3)$ & \multicolumn{4}{|c|}{$1.5(0.0)$} \\
\hline$n$ & 18 & 24 & 18 & 15 & 18 & \multicolumn{4}{|c|}{60} \\
\hline
\end{tabular}

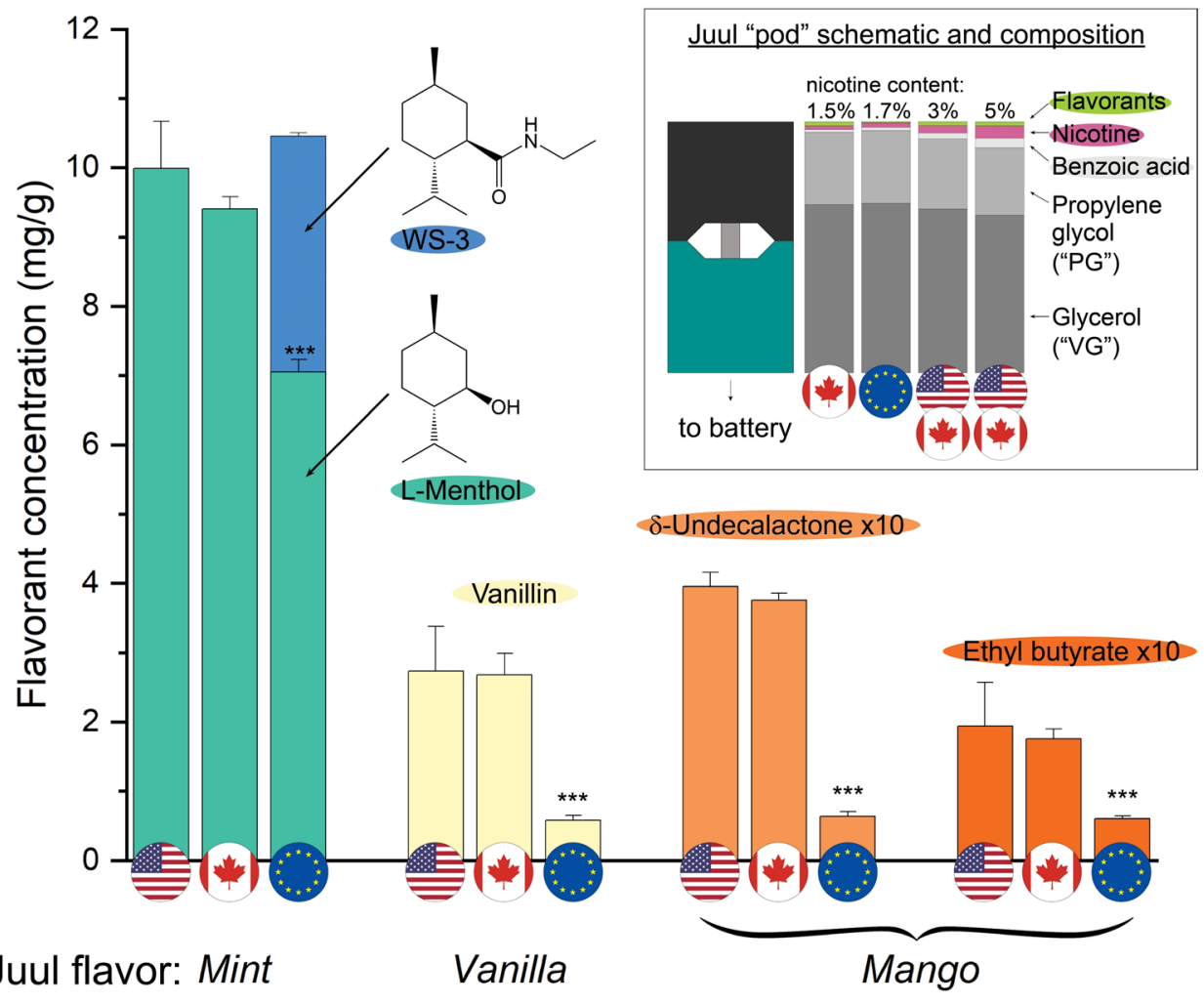

Figure 1 Mean $(95 \% \mathrm{Cl})$ of principal flavourant concentrations in Juul e-liquids (menthol in 'mint' flavour, vanillin in 'Vanilla'a flavour,

$\delta$-undecalactone and ethyl butyrate in 'mango' flavour) purchased in the USA, Canada (CA), and the European Union (EU, samples from UK, France, Italy, Germany). The synthetic coolant WS-3 was only found in EU mint flavour (blue BAR). Flavourant concentrations were measured in pods of 'mint', 'vanilla' and 'mango' flavours of all available nicotine concentrations ${ }^{b}$ in triplicate (USA: $n=6 ; C A: n=9$, EU: $n=12$ ). One-way ANOVA with Bonferroni post-tests showed no significant differences between USA and CA flavourant concentrations. ${ }^{* *} \mathrm{P}<0.001$. Insert: schematic of a Juul e-liquid 'pod', and approximate content composition in weight- $\%$ depending on country of sale and resulting nicotine content of pod: Glycerol (63\%-67\%), propylene glycol $(27 \%-29 \%)$, benzoic acid $(1.1 \%-3.8 \%)$, nicotine $(1.5 \%-5 \%)$, flavourants $(0.1 \%-1.5 \%)$. The flavourant content is estimated and depends on the flavour. Bar graphs represent composition of the homogeneous e-liquid mixture and do not indicate spatial location. ${ }^{a} \mathrm{Name}$ differs by country, see table 1. ${ }^{\mathrm{b}}$ Available nicotine concentrations by country (in wt.- $\%$ ): USA: 3\%, 5\%; CA: 1.5\%, 3\%, 5\%; EU: 1.7\%. ANOVA, analysis of variance; WS-3, N-ethyl-p-menthane-3-carboxamide. 
$200 \mathrm{mAh}$ (battery capacity), $1.7 \mathrm{ohm}$ (coil resistance), resulting in maximum power output of $\sim 8$ watts.

\section{DISCUSSION}

While the e-liquid compositions differed between US/Canadian and EU Juul e-liquids, the device power output between countries did not. As a result, nicotine aerosol delivery can be expected to be proportional to the e-liquid nicotine content, which EU regulation caps at roughly one-third of the highest concentration available in the USA/Canada (1.7\% vs 5\%). However, continued monitoring of devices on the European market may be warranted since increasing power output could be a strategy by manufacturers to deliver more nicotine to users while complying to EU regulations on e-liquid nicotine content. Another question is how e-cigarette regulation including e-liquid nicotine content limits may change in the UK following its recent exit from the EU ('brexit').

Similar to nicotine, principal flavourant concentrations are reduced in EU 'Vanilla' and 'Mango' e-liquids (figure 1). Possible explanations are that lower concentrations of flavourants suffice to mask the irritancy and bitter taste of lower nicotine EU e-liquids or that European user panels preferred products with lower flavour intensities in market tests. It is plausible that this is also the reason why European 'Mango' flavour does not contain the intensely sweet 'cotton candy' flavourant ethyl maltol found in US/Canadian Juul 'Mango' flavour, but rather the only 'slightly' sweet benzyl alcohol. ${ }^{45}$ In addition, US/Canadian Juul 'Mango' e-liquid contains an emulsifier, triethyl citrate, which is absent in the EU product. Triethyl citrate is likely necessary to solubilise the more highly concentrated mango flavourants and keep the e-liquid homogeneous. Study limitations include quantifying only selected flavourants and possible non-detection of high molecular weight flavourants.

Importantly, while not present in US Juul 'Mint' flavour, the synthetic coolant WS-3 was found in EU 'Mint' e-liquid (figure 1). Synthetic coolants elicit cooling sensations without the 'minty' odour and harshness of menthol. ${ }^{6}$ Reducing menthol intensity may be favourable in the European market where menthol cigarette use is less prevalent than in the USA, ${ }^{7}$ with WS-3 added to EU Juul 'Mint' e-liquid to compensate for lost cooling effect from reduced menthol content. Similar to menthol, WS-3 activates TRPM8, the cold/menthol receptor in sensory neurons, a mechanism known

\section{What this paper adds}

- Synthetic coolants elicit a similar 'cooling' effect as menthol without the distinctive odour of menthol.

- Juul has expanded sales to several countries yet it is unclear if the e-liquid formulation was adapted to specific markets beyond adhering to local restrictions on nicotine content, such as the limit of $20 \mathrm{mg} / \mathrm{mL}$ in the European Union.

- In European, Juul 'Mint' e-liquid, reduced menthol levels and the resulting loss of cooling effect are compensated by the addition of the synthetic coolant WS-3 (N-ethyl-p-menthane3-carboxamide), the inhalational safety of which is unknown.

- European Juul e-liquid 'pods' contain lower amounts of principal flavour molecules in popular 'Vanilla', 'Mango' and 'Mint' e-liquids when compared with US/Canadian marketed 'pods' of the same flavours.

- No difference in device power output was found between European, US and Canadian Juul devices, suggesting that nicotine delivery to the aerosol can be expected to be proportional to e-liquid nicotine content. to suppress irritation from smoke and nicotine. ${ }^{8}$ While WS-3 is approved for use in foods, little is known about its inhalational safety. Notably, WS-3 and other synthetic coolants are explicitly banned from use in combustible tobacco products in Germany ${ }^{9}$ and Canada. ${ }^{10}$ Possible related health concerns of WS-3 and synthetic coolants in general should be addressed by future research as well as by regulators, and any actions targeting menthol should be extended to synthetic coolants as they trigger similar sensory responses.

Contributors HCE and JBZ designed the study. HCE collected and analysed the data, and drafted the manuscript with input from PTA, SEJ and JBZ. All authors critically reviewed, edited and approved the final manuscript. JBZ is the guarantor of the paper. JBZ attests that all listed authors meet authorship criteria and that no others meeting the criteria have been omitted.

Funding This work was supported by grants P50DA036151 and U54DA036151 (Yale Centre for the Study of Tobacco Product Use and Addiction: Flavors, Nicotine and Other Constituents) from the National Institute on Drug Abuse and FDA CenterCentre for Tobacco Products (CTP), and grant R01ES029435 from the National Institute of Environmental Health Sciences (NIEHS) of the National Institutes of Health (NIH).

Disclaimer The sponsors had no role in the design and conduct of the study; collection, management, analysis, and interpretation of the data; preparation, review, or approval of the manuscript; and decision to submit the manuscript for publication. The content is solely the responsibility of the authors and does not necessarily represent the views of the $\mathrm{NIH}$ or the FDA.

Competing interests Unrelated to the current work, over the past 3 years SO reports: having been a consultant or an advisory board member for Alkermes, Amygdala, Indivior, Mitsubishi Tanabe and Opiant; an NIDA Clinical Trials Network DSMB member with honorarium from the Emmes Corporation; having received donated study medications from Astra Zeneca, Pfizer and Novartis; and being a member of the American Society of Clinical Psychopharmacology's Alcohol Clinical Trials Initiative (ACTIVE Group) supported in the past 3 years by Alkermes, Amygdala Neurosciences, Ethypharm, Indivior, Lundbeck, Mitsubishi, and Otsuka; Unrelated to the current research, SEJ reports receiving personal fees and nonfinancial support from Hydra Biosciences and Sanofi and nonfinancial support from GlaxoSmithKline Pharmaceuticals; Unrelated to the current research, SK-S reports receiving donated study medications from Novartis, Astra-Zeneca and Pfizer.

Patient consent for publication Not required.

Provenance and peer review Not commissioned; externally peer reviewed.

Data availability statement All data relevant to the study are included in the article.

Open access This is an open access article distributed in accordance with the Creative Commons Attribution Non Commercial (CC BY-NC 4.0) license, which permits others to distribute, remix, adapt, build upon this work non-commercially, and license their derivative works on different terms, provided the original work is properly cited, appropriate credit is given, any changes made indicated, and the use is non-commercial. See: http://creativecommons.org/licenses/by-nc/4.0/.

\section{ORCID iD}

Hanno C Erythropel http://orcid.org/0000-0003-3443-9794

\section{REFERENCES}

1 Erythropel HC, Davis LM, De Winter TM, et al. Presence and Vapor-Delivery of flavor Aldehyde-Solvent reaction products, nicotine, and menthol in Juul e-cigarettes. Am J Prev Med 2019;57:425-7

2 EU tobacco products Directive, 2014/40/EU, L127/1 2014

3 Erythropel HC, Jabba SV, DeWinter TM, et al. Formation of flavorant-propylene glycol adducts with novel toxicological properties in chemically unstable e-cigarette liquids. Nicotine Tob Res 2019;21:1248-58.

4 Nair B. Final report on the safety assessment of benzyl alcohol, benzoic acid, and sodium benzoate. Int J Toxicol 2001;20:23-50.

5 Surburg H, Panten J. Common fragrance and flavor materials: preparation, properties and uses. Berlin, Germany: John Wiley \& Sons, 2016.

6 Watson HR, Hems R, Rowsell DG, et al. New compounds with menthol cooling effect. J Soc Cosmet Chem 1978;29:185-200.

7 Paschke M, Tkachenko A, Ackermann K, et al. Activation of the cold-receptor TRPM8 by low levels of menthol in tobacco products. Toxicol Lett 2017:271:50-7.

8 Willis DN, Liu B, Ha MA, et al. Menthol attenuates respiratory irritation responses to multiple cigarette smoke irritants. Faseb J 2011;25:4434-44.

9 Verordnung über Tabakerzeugnisse und verwandte Erzeugnisse (Tabakerzeugnisverordnung - TabakerzV), Anlage 1 In. Berlin, Germany 2016.

10 Order amending the schedule to the tobacco act (menthol) in. Ottawa, ON 2017 